\title{
Ependymal cyst of the spinal cord: case report
}

\author{
HUGH S. WISOFF ${ }^{1}$ AND NITYA R. GHATAK
}

From the Department of Neurological Surgery and the Lucy and Henry. Moses Research Laboratories of the Laboratory Division, Montefiore Hospital and Medical Center, and the Albert Einstein College of Medicine, Bronx, New York, U.S.A.

SUMMARY A subarachnoid ependymal cyst of the spinal cord is rarely reported. A 44 year old man with a cyst compressing the lower spinal cord and conus medullaris is described. Excellent $\stackrel{\Phi}{\Omega}$ functional recovery followed excision of the lesion. The cells lining the cyst were histologically indistinguishable from normal ependymal cells, but, unlike the normal ependymal cells which are $\vec{\circ}$ related to subependymal glial tissue, the cells lining the cyst abutted directly on the connective tissue forming the cyst wall. This is in contrast with ependymal lined cysts occurring within the conus $\vec{\omega}$ medullaris, and intradural teratomatous cysts which consistently contain intracytoplasmic mucinous material. It is postulated that an ependymal cyst could result from isolation of ependymal cells from either the roof or floor plates during embryogenesis of the neural tube.

An ependymal cyst of the spinal cord is a rare lesion Two case reports have appeared in the literature. Hyman, Hamby, and Sanes (1938) described a single case of an ependymal cyst of the anterior aspect of the cervicodorsal region of the spinal cord in a 7 year old boy. Radiographs showed dilatation of the cervical canal, flattening of the pedicles, and a fusion defect of the laminae of $\mathrm{C7}$ and T1 vertebrae. The child made a good postoperative recovery after partial excision of the cyst wall. Moore and Book (1966) reported a 17 year old boy who, after a neck injury, developed symptoms of a cervical cord lesion. Radiographs showed fusion, narrowing of the bodies of $\mathrm{C} 3,4$, and 5 vertebrae and dilatation of the spinal canal. There was spina bifida of $\mathrm{C} 7$ and $\mathrm{T} 1$ vertebrae. At laminectomy, a cyst ventral to the spinal cord was partially excised and the patient made a good postoperative recovery. Moore and Book (1966) discussed the case report by Hoffmann (1960) describing a 6 year old boy with a cyst anterior to the cord. This was called an arachnoidal cyst, but it was in truth an ependymal cyst as judged from both the microscopic description and illustrations.

\section{CASE REPORT}

A 44 year old white male was admitted to Montefiore Hospital and Medical Center on 16 August 1969. On 3

${ }^{1}$ Address for reprints: 27 Ludlow Street, Yonkers, New York 10705, U.S.A.
July 1969 , while carrying loaded trays at work, he had the onset of severe low back pain, associated with pain in the right buttock which gradually progressed to radiatiog $O$ into the right thigh. The pain subsequently radiated into both thighs and he was hospitalized elsewhere on 29 July 1969 with a presumptive diagnosis of herniated dise He was treated with bed rest and pelvic traction without $\overrightarrow{0}$ improvement. In early August 1969, he required insertiont of an indwelling Foley catheter because of inability to void. He was known to have retinitis pigmentosa for 25 . years and was totally blind as a result. It was thought that the right leg was always smaller than the left.

Examination on admission showed paraparesis, with greatest weakness in the gastrocnemius muscles, fascicu- $\frac{\mathscr{D}}{D}$

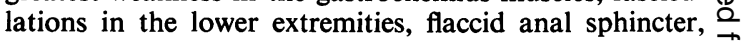
hyperactive knee jerks, and absent ankle jerks. The $\overrightarrow{\overrightarrow{0}}$ plantar responses were silent. There was saddle hypalgesia. $\exists$ The patient was totally blind. There were no cutaneous
abnormalities.

Plain radiographs of the spine showed thinning of the pedicles of the first and second lumbar vertebrae (Fig. 1). Myelography showed a complete block of the Pantopaque column at $\mathbf{L} 1$ vertebral level with a 'tumour cap' (Figs. 2 and 3). The cerebrospinal fluid was yellow and clotted spontaneously.

Laminectomy of T12, L1, and L2 vertebrae was carried out under general anaesthesia on 19 August 1969. Epidural fat was absent at the level of $L 1$ vertebra and the dura mater was very tense. After the dura mater was $\frac{7}{0}$ opened, the arachnoid mater appeared to be unusually grey and opaque. After this membrane was opened, it was $N$ evident that a thin-walled cyst measuring $3 \mathrm{~cm}$ in length was compressing the lower spinal cord and conus $N$ medullaris (Fig. 4). The cyst was punctured and emptied 


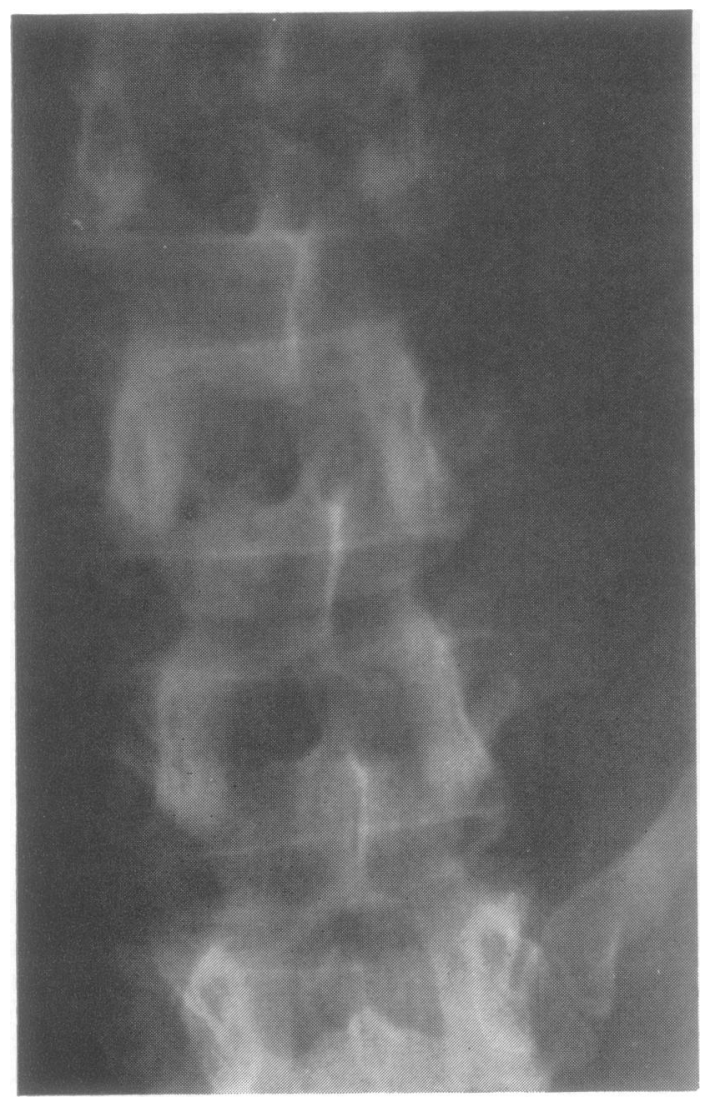

FIG. 1. Anteroposterior radiograph of upper lumbar spine showing thinning of pedicles of L1 and L2 vertebrae.

of clear fluid. The base was attached intimately to the cord substance. The lesion was excised completely except for its attachment to the spinal cord.

Postoperatively, the patient made an excellent recovery, and he left the hospital on 6 September 1969 and returned to full-time work six weeks later. There was residual atrophy of the right leg, the right knee jerk was less active, and the ankle jerks absent. There were no Babinski signs. There were no urinary disturbances.

SPECIMEN The cyst wall consisted of a semi-translucent membranous tissue with a smooth, glistening, luminal surface. The external surface was uneven and embedded with several fragments of nerve roots which were densely adherent to the cyst wall. Sections of the cyst wall were stained by haematoxylin and eosin ( $\mathrm{H}$ and $\mathrm{E}$ ), reticulin, phosphotungstic acid haematoxylin (PTAH), luxol fast blue, PAS, and mucicarmine methods.

Microscopically, the cyst wall was composed of a narrow band of fibrocollagenous tissue with a continuous lining of a single layer of cells ranging from tall columnar

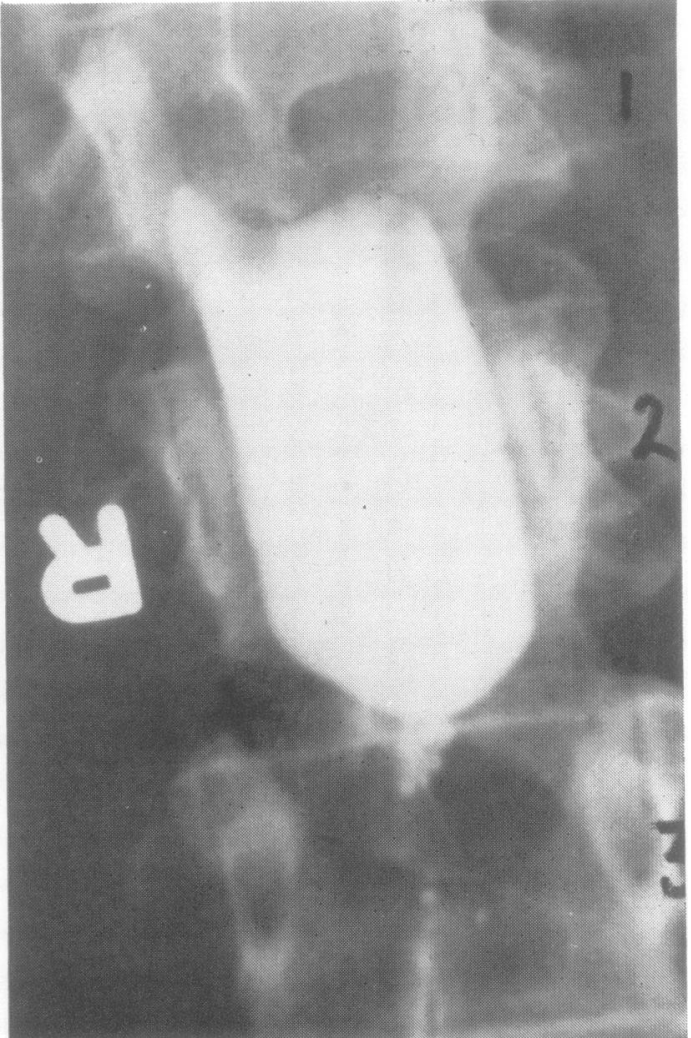

FIG. 2. Posteroanterior view of myelogram showing complete block opposite LI vertebra.

to low cuboidal in type (Fig. 5). In some areas, however, the lining cells appeared to be piled up due to oblique plane of section. The individual cells showed uniform and mostly basally orientated nuclei and homogeneous eosinophilic cytoplasm. Only an occasional cell showed small amounts of mucicarmine positive material. The free margins of most of the cells displayed tufts of cilia (Fig. 6). An indistinct basement membrane could be recognized in some areas between the cells and fibrous wall. No glial tissue was seen anywhere in the wall. However, minute twigs of peripheral nerve fibres were seen densely adherent to the cyst wall (Fig. 5).

\section{DISCUSSION ON PATHOLOGY}

The cells lining the cyst were histologically indistinguishable from the ependymal cells seen in the brain and spinal cord. It should be noted, however, that, unlike the normal ependymal cells which are related to subependymal glial tissue, the cells lining the cyst 


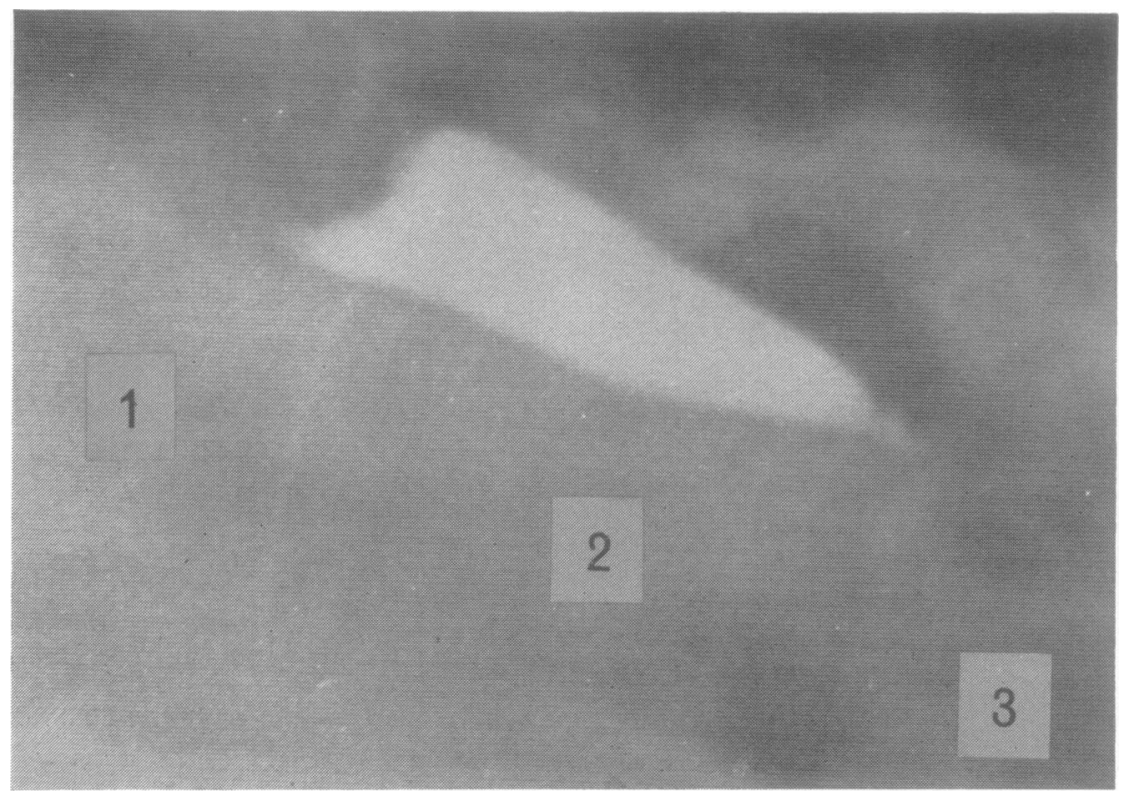

FIG. 3. Lateral view of myelogram.

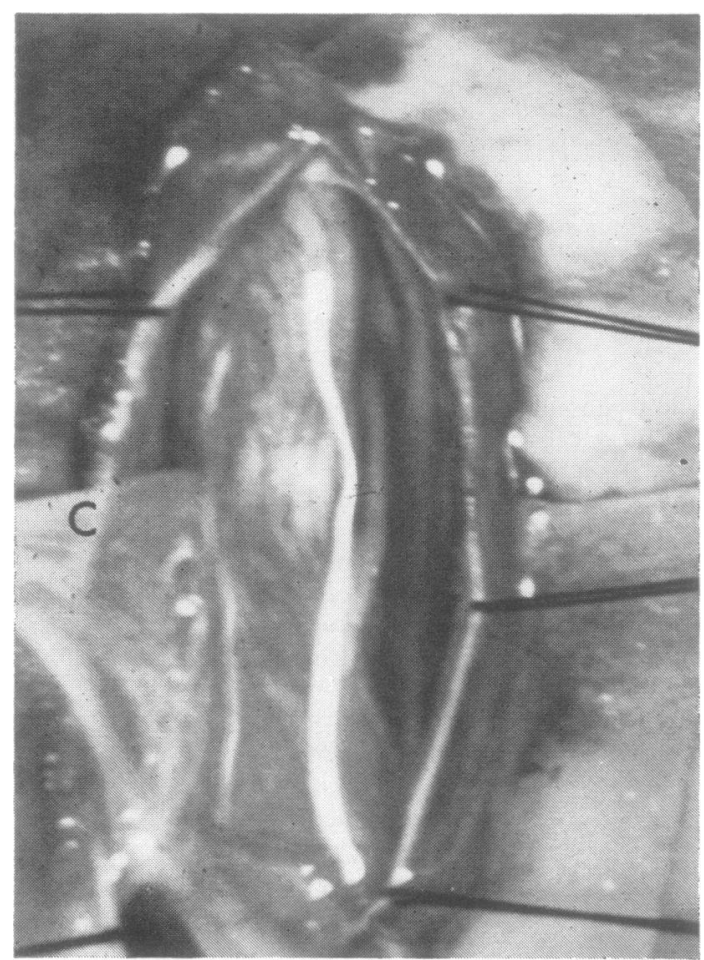

FIG. 4. Operative photograph showing collapsed cyst (C) still attached to surface of spinal cord. abutted directly on the connective tissue forming the cyst wall. This is in contrast with the ependymal line cysts occurring in the conus medullaris as reported by Nassar, Correll, and Housepian (1968). In one \&fo the three cases reported by these authors, micrescopic examination of the cyst wall showed a laysir $\overrightarrow{0}$ of ependymal cells situated along one surface $\overrightarrow{\text { of }} \stackrel{\overrightarrow{ }}{ }$ narrow bands of glial tissue. Interestingly, ciliated columnar cells lining a fibrous cyst wall, as described here, closely resemble the teratomatous cysts located intradurally in the spinal canal as reported by Rewcastle and Francoeur (1964). However, frequent $\frac{\mathrm{Q}}{\mathrm{Q}}$ stratification of the lining cells (with prominent intercellular bridges in one case) and more con-을 spicuous intracytoplasmic mucinous material in these teratomatous cysts tend to distinguish these cysts from the ependymal lined cyst as described in this: report.

\section{CLINICAL DISCUSSION}

Hyman et al (1938) called attention to the resem- $\frac{\hat{\delta}}{3}$ blance of a spinal ependymal cyst to those described associated with the cerebral ventricles. It is thoughto that the cerebral cyst developed within rests of ependymal cells which result from evaginations of the ventricular lining into the brain substance. If the N connecting stalk becomes obliterated, an island of ependymal tissue may be left completely isolated from the ventricles. At certain stages in the normal $\omega$ 


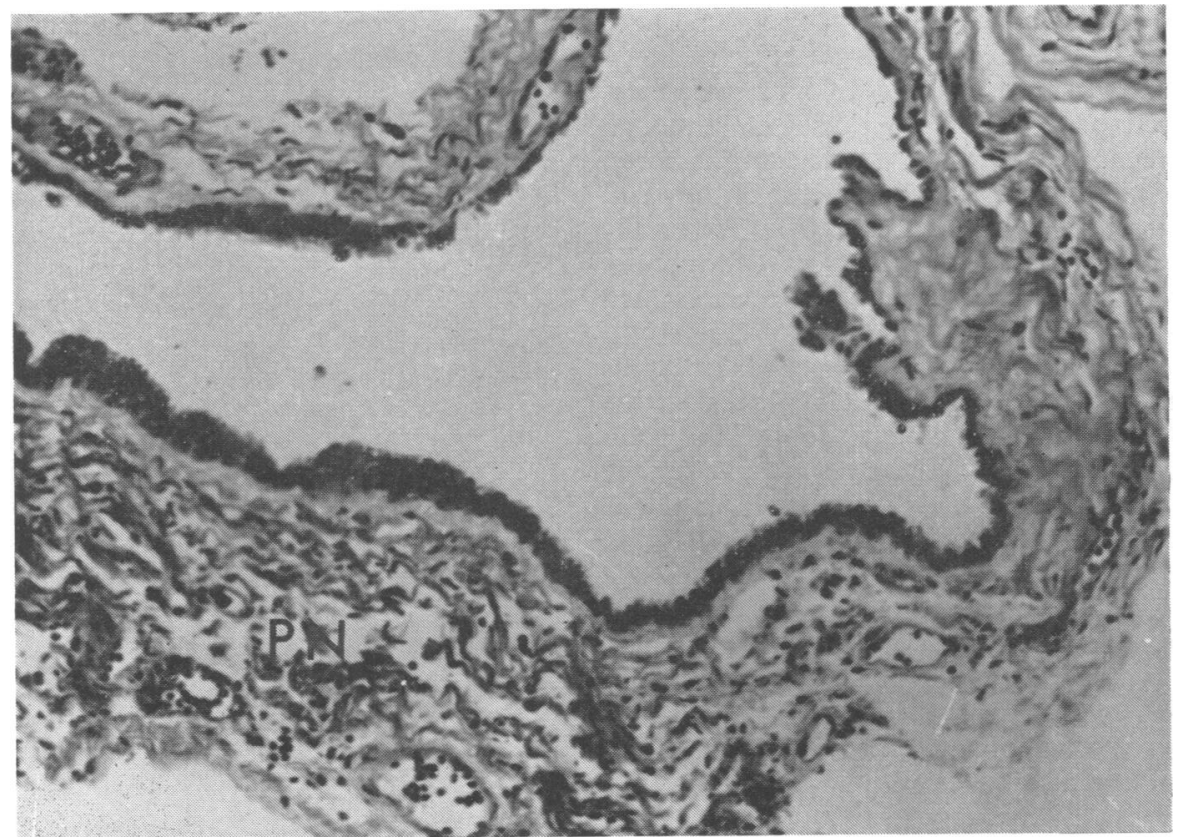

FIG. 5. Lower power view of the cyst wall showing columnar and cuboidal cells on the luminal surface of the fibrocollagenous wall. Note a small fragment of peripheral nerve (PN) adherent to the cyst wall. $H$ and $E . \times 170$

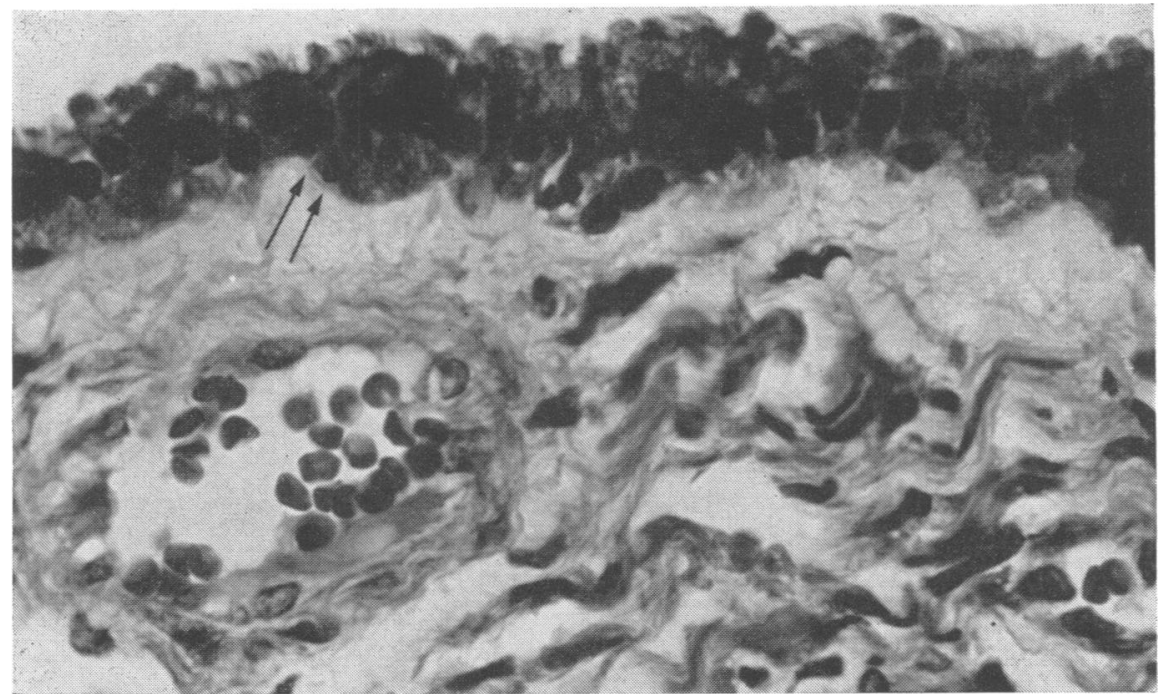

FIG. 6. High power view of the cells lining the cyst showing distinct cilia at the free margins. Indistinct basement membrane separates the cells from the fibrous cyst wall (arrows). $H$ and $E, \times 680$. 
embryogenesis of the neural tube, the roof and floor plates consist essentially of a single layer of ependymal cells. Even when fully developed, the plates are increased only slightly in thickness, although they become buried in the dorsal and ventral fissures. It is postulated that an ependymal cyst could result from isolation of ependymal cells from either the roof or floor plates with secondary cyst formation. The cysts in the two prior case reports were located on the anterior surface.

Trauma was associated with the onset of symptoms in both Moore and Book's case (1966), and in the one reported currently. Though Moore and Book did not feel that the trauma was responsible for the formation of the cyst, they did suggest that the injury precipitated the symptoms. They found haemosiderin-filled phagocytes in the wall of the cyst indicative of prior haemorrhage. An alternative explanation is a disturbance of the hydrodynamic forces in the subarachnoid space as a result of injury.

The plain radiographs of the spine have shown enlargement of the spinal canal in all reported cases. In the two prior case reports, there were fusion defects in the laminae overlying the lesion in the lower cervical region. Myelography has been the diagnostic study of choice, and the findings have not been distinctive for a cystic lesion.

It is felt that there is no relationship between the current patient's retinitis pigmentosa and the subarachnoid ependymal cyst of the spinal cord.

The differential diagnosis of an intradural cyst of the spinal cord includes arachnoidal cyst (Hoffmann,
1960), enterogenous cyst (Harriman, 1958, ando Scoville, Manlapaz, Otis, and Cabieses, 1963), teratomatous cyst (Kubie and Fulton, 1928, andes Rewcastle and Francoeur, 1964), intramedullaryo cystic lesions, including syringomyelia and dilatation and hernial protrusion of the central canal of the cord (Elsberg, 1925), and parasitic infestations.

\section{REFERENCES}

Elsberg, C. A. (1925). Tumors of the Spinal Cord and the Symptoms of Irritation and Compression of the Spinal Cord and Nerve Roots; Pathology, Symptomatology, Diagnosis $\overline{\bar{c}}$ and Treatment. p. 322. Hoeber: New York.

Harriman, D. G. (1958). An intraspinal enterogenous cyst. J. Path., 75, 413-419.

Hoffmann, G. T. (1960). Cervical arachnoidal cyst-report of a 6 year old Negro male with recovery from quadriplegia. $\vec{\circ}$ J. Neurosurg., 17, 327-330.

Hyman, I., Hamby, W. B., and Sanes, S. (1938). Ependymal $\vec{\omega}$ cyst of the cervicodorsal region of the spinal cord. Arch. Neurol. Psychiat. (Chic.), 40, 1005-1012.

Kubie, L. S., and Fulton, J. F. (1928). A clinical and pathological study of two teratomatous cysts of the spinal cord, containing mucus and ciliated cells. Surg. Gynec. Obstet., 47, 297-311.

Moore, M. T., and Book, M. H. (1966). Congenital cervicit or ependymal cyst. Report of a case with symptoms pre के cipitated by injury. J. Neurosurg., 24, 558-561.

Nassar, S. I., Correll, J. W., and Housepian, E. M. (196\&. 금 Intramedullary cystic lesions of the conus medullaris. J. Neurol. Neurosurg. Psychiat., 31, 106-109.

Rewcastle, N. B., and Francoeur, J. (1964). Teratomatous $\frac{\rho}{\square}$ cysts of the spinal canal; with 'sex chromatin' studie Arch. Neurol. (Chic.), 11, 91-99.

Scoville, W. B., Manlapaz, J. S., Otis, R. D., and Cabies.; F. (1963). Intraspinal enterogenous cyst. J. Neurosurg., 29, 704-706. 